\title{
A comparative study of conventional Milligan-Morgan hemorrhoidectomy versus harmonic scalpel hemorrhoidectomy
}

\author{
Hesham M Hasan, MD \\ Department of General Surgery, Ain Shams University, Cairo, Egypt.
}

\begin{abstract}
Hemorrhoidal disease is one of the most common anorectal disorders, affecting, in various forms, almost 50\% of people over the age of fifty. Surgical treatment is considered the standard treatment for grade III and IV hemorrhoids. However, although it is considered a minor procedure, the post-operative course is protracted, and the post-operative complications are not negligible. The resulting pain-related complications after conventional hemorrhoidectomy $(\mathrm{CH})$ are often the major factors that prolong hospital stay and delayed recovery. Recently various new treatment modalities have been developed with the aim of overcoming post-operative pain, such as stapled hemorrhoidopexy, Ligasure, and harmonic scalpel, sealing devices. The aim of this study is to evaluate and compare the conventionalMilligan-Morgan hemorrhoidectomy $(\mathrm{CH})$ with harmonic scalpel hemorrhoidectomy $(\mathrm{HSH})$ on eighty four patients with symptomatic grade III or IV hemorrhoids operated on at the Department of General Surgery, AL-Jedaani hospital, Jeddah, Saudi Arabia, between May 2008 and January2011. The patients were randomly allocated to undergo either a $\mathrm{CH}$ (group] $=42$ patients) or HSH (group 2=42 patients). After analyzing the data collected from this study we can conclude that; hemorrhoidectomy with harmonic scalpel can provide a safe, fast, low-morbidity alternative to conventional hemorrhoidectomy.
\end{abstract}

Key words: Harmonic scalpel, Milligan- Morgan, hemorrhoidectomy.

\section{Introduction:}

Hemorrhoidal disease is one of the most common anorectal disorders, affecting, in various forms, almost $50 \%$ of people over the age of fifty and is one of the surgical problems which still there is a lot of debate regarding the best management for it.1 Hemorrhoidectomy is superior to any proposed conservative procedure, including rubber band ligation, sclerotherapy, photocoagulation, and cryotherapy for treating symptomatic grades III and $\boldsymbol{N}$ hemorrhoids.2 Unfortunately, it is usually associated with significant postoperative complications, including pain, bleeding, and anal stricture, which can result in a protracted period of convalescence. 3 Throughout the years, several modifications have been made to the original operation of excision of hemorrhoids using scissors to improve outcomes, especially postoperative pain after the procedure.The Milligan-Morgan open hemorrhoidectomy is the most widely practiced technique and is considered by many to be the current standard for surgical management ofhemorrhoids. ${ }^{4}$ This traditional approach is effective; however, it is often accompanied by a high incidence of complications, such as urinary retention, hemorrhage, and significant pain.5 Recent advances in instrumental technology, including the bipolar electrothermal device, ultrasonic scalpel, and circular stapler, are gaining popularity as effective alternatives in hemorrhoidectomy.6 Surgical excision using the harmonic scalpel is a more recent technique for use in symptomatic third- and fourth-degree hemorrhoids. Ithas been advocated in a number of other surgical procedures to decrease bleeding and minimize operating room time.7 Harmonic scalpel works through the denaturation of proteins by breaking hydrogen bonds, thereby forming a coagulum to seal 
vessels at lower temperatures and decreasing thermal damage to surrounding tissues. 8 When used in hemorrhoidal surgery, the resulting mucosal defect created by excising the hemorrhoid is then left open or sutured closed depending on surgeon preference. It has been reported that harmonic scalpel is superior to bipolar scissors because of less post-operative pain.9 The aim of this study is to evaluate and compare the $(\mathrm{CH})$ with $(\mathrm{HSH})$ in surgical management of third and fourth degree hemorrhoids. The two different techniques will be compared as regards surgical outcome, postoperative pain, hospital stay, post-operative bleeding, wound infection, healing, fistula formation, stricture, and anal incontinence.

\section{Patients and methods:}

This study was carried on eighty four patients with symptomatic grade III or IV hemorrhoids operated on at the Department of general Surgery, AL- Jedaani hospital, Jedclah, Saudi Arabia, between May 2008 and January2011. Written informed consent was obtained from all patients after full explanation of the procedure. The exclusion criteria included patients on anticoagulants, patients with hematological disorder, concomitant anal disease, or a previous history of anorectal surgery. The patients were randomly allocated to undergo either a conventional MilliganMorgan hemorrhoidectomy (group I= 42 patients) or harmonic scalpel hemorrhoidectomy (UltraCision ( ${ }^{\circ}$ 10-mm Coagulating Shears, Ethicon Endo-Surgery, Inc., Cincinnati, OH) (group $11=42$ patients). The operation was performed under general

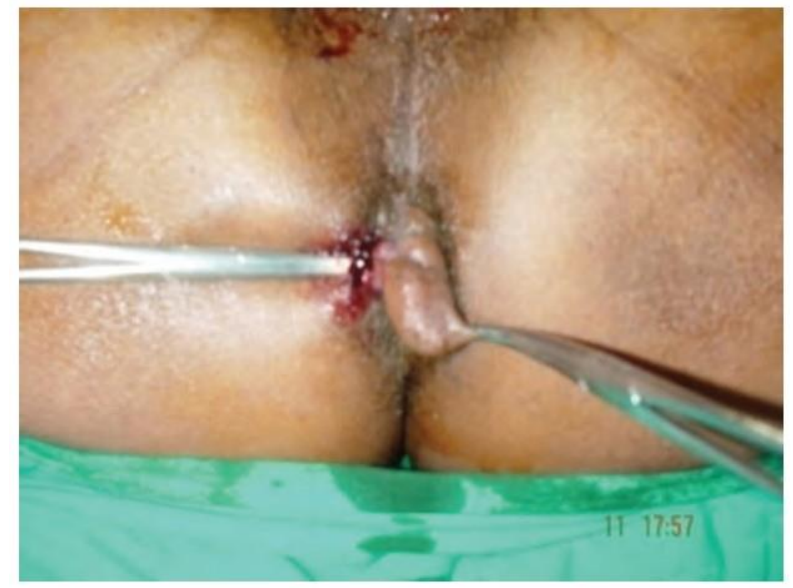

Figure (1): The internal and external components of each hemo"hoid. or spinal anesthesia at the discretion of the anesthetist. The patients were placed in lithotomy position. The internal and external components of each hemorrhoidal complex were first grasped and elevated using artery forceps, Figure(l) a skin incision at the junction of the hemorrhoid and the flat perianal skin was made by a scalpel, followed by the dissection of the hemorrhoid bundles off the underlying sphincter using electrocautry in group I Figure(2) or harmonic scalpel in group II Figures(3,4). The harmonic scalpel device was applied along the curvature of the artery forceps with its own curvature facing into the lumen of the anal canal to minimize potential injury to the sphincter muscles. Finally, the hemorrhoidal pedicle was ligated by $2 / 0$ silk suture in group I or sealed and divided by harmonic scalpel in group II. The naked area was then inspected well to ensure complete hemostasis Figures(5,6). For postoperative pain relief, intramuscular non steroidal anti inflammatory Diclofenac sodium (75 mg) was prescribed twice a day for all patients.Additional parenteral analgesics would be administrated when patients complained of pain intolerance. The pain score was evaluated by means of the visual analog score (0-10). The two groups were compared also for postoperative bleeding, post-operative wound healing, post-operative hospital stay, anal stenosis, wound infection, fistula formation, or incontinence. Follow-up was performed at one, two, four, six, eight, and twelve weeks to detect post-operative complications and time offwork in all84 patients.

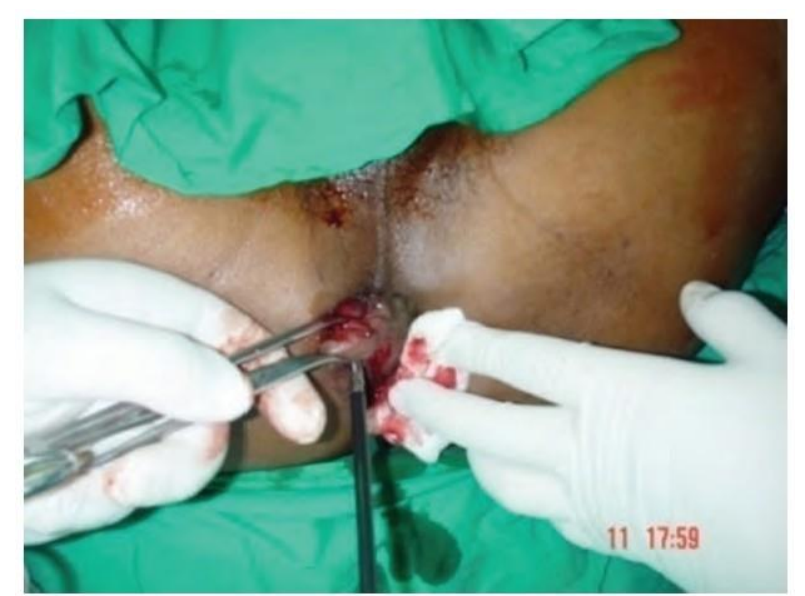

Figure (2): Dissection of the hemorrhoid bundles using electrocautry. 


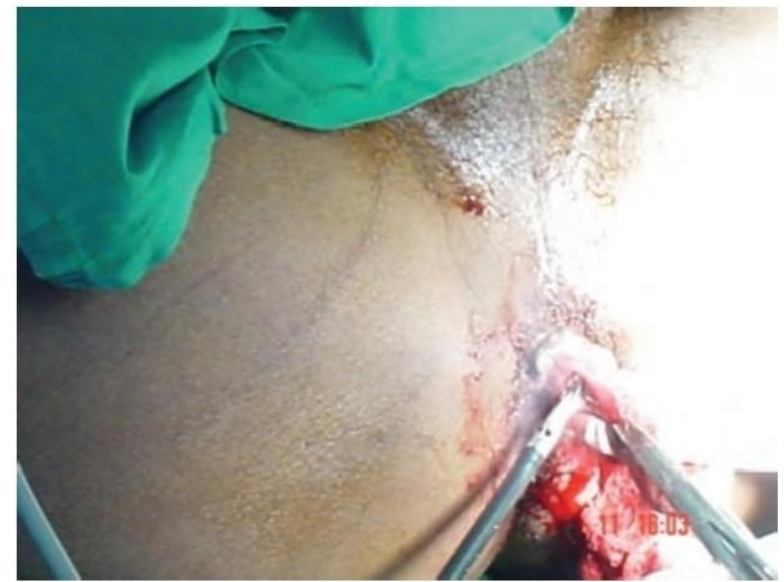

Figure (3): Dissection of the hemorrhoid bundles using harmonic scalpel.

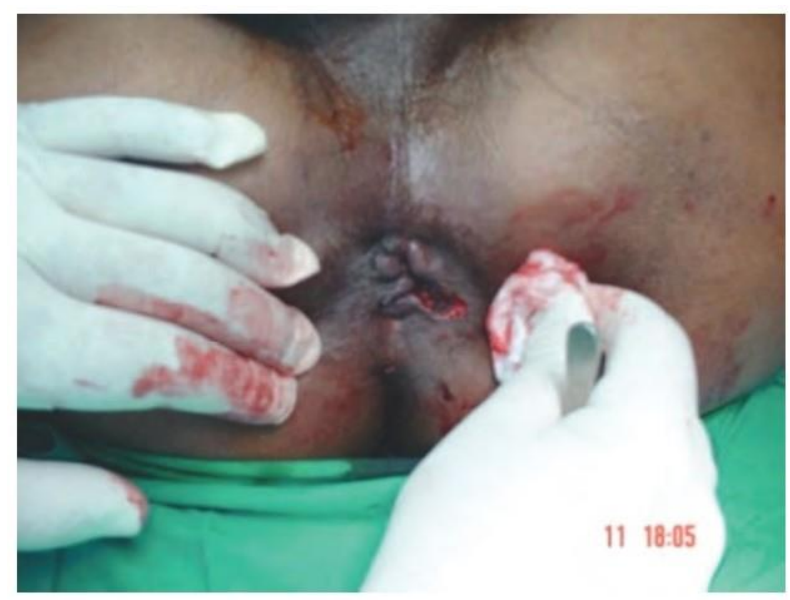

Figure (5): Inspection to ensure complete hemostasis.

Results

Over a 32-months period, 84 patients were included in this study. 42 patients underwent hemorrhoidal excision via a conventional Milligan- Morgan hemorrhoidectomy (group I) another 42 patients underwent hemorrhoidal excision via the harmonic scalpel

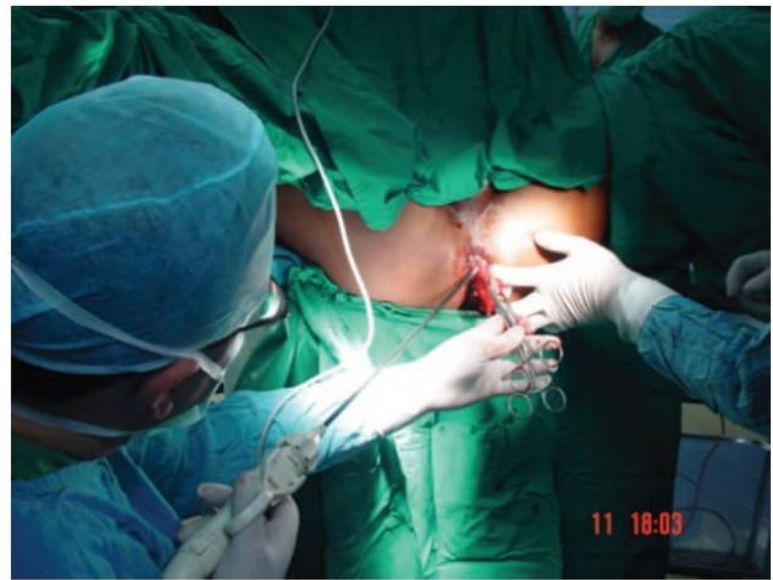

Figure (4): Dissection of the hemorrhoid bundles using harmonic scalpel.

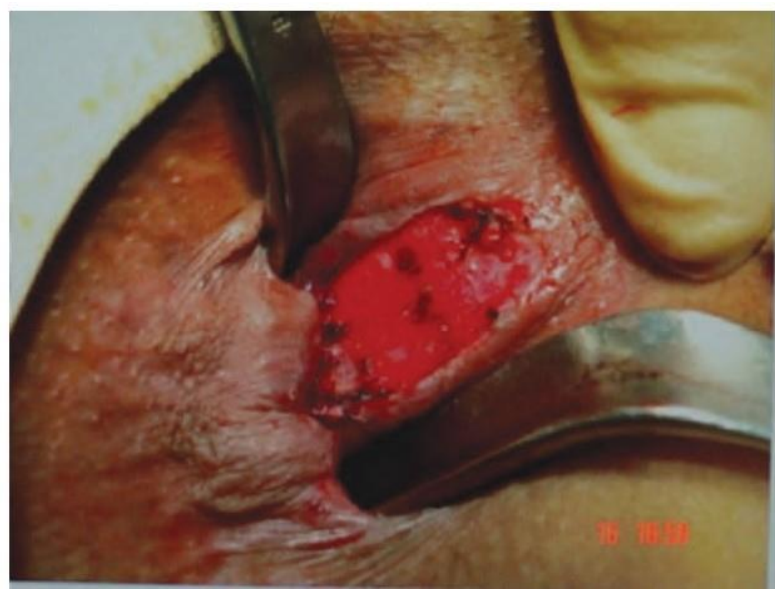

Figure (6): Inspection to ensure complete hemostasis.

hemorrhoidectomy (group II). Mean followup period was 12.5 (range, 9-21) months. The two groups were matched for age and gender distribution Table(1). There was no statistical difference in the duration of symptoms and the severity of hemorrhoids between the two groups.

Table (1): Demographic data.

\begin{tabular}{|l|l|l|l|}
\hline Parameter & Group 1 & Group2 & P value \\
\hline No. ofpatients & 42 & 42 & \\
\hline Sex ratio (M:F) & $29: 13$ & $27: 15$ & $\begin{array}{l}\mathrm{X} 2=() .214, \\
\mathrm{p}=() .6434>0.05, \\
\mathrm{NS}\end{array}$ \\
\hline $\begin{array}{l}\text { Age (yr), median } \\
\text { and range }\end{array}$ & $40.2(18-58)$ & $41.2(21-62)$ & $\begin{array}{l}\mathrm{t}=0.482, \\
\mathrm{p}=() .631,>0.05 \\
\mathrm{NS}\end{array}$ \\
\hline
\end{tabular}

$N S=$ non significant 
There was no significant difference between the two groups in number of hemorrhoidal columns excised. The mean operating time, was significantly longer in group I (16.9 $\pm 4.4 \mathrm{~min}$.) than group II (14.4 $\pm 2.5 \mathrm{~min}$.) $(\mathrm{P}<0.01)$. Twenty patients $(47.6 \%)$ of group I needed opioid analgesia in addition to, intramuscular non steroidal anti inflammatory (Diclofenac sodium $75 \mathrm{mg}$ ) as they were not tolerating pain post operatively. While nine patients only in group II $(21.4 \%)$ need opioid analgesia post operatively. Lower pain scores (2.37 \pm 0.85$)$ were observed in the HSH group than in the $\mathrm{CH}$ group $(4.77 \pm 0.86)$. Pain on postoperative day 1 was measured by the Visual Analogue Scale (VAS). A score ofO represents no pain, while a score of 10 represents the worst pain. Significant postoperative bleeding occurred in three cases $(7.1 \%)$ in group I after discharge from hospital (around the 5th-6th day). One patient needed readmission in hospital with blood transfusion and reoperation to control bleeding. Conservative treatment \{compression and local ice) was sufficient to control bleeding in the other two patients. In group II no postoperative bleeding were observed. In group I only one patient $(2.5 \%)$ developed infection which occurred at the surgical site. The patient was treated at home with oral antibiotic therapy (ciprofloxacin 1.0 g/day + metronidazol 1.5 g/day, 7 days).

Four patients in group I and three patients in group II developed urinary retention; all 7 patients with urinary retention had spinal anesthesia. There was no significant difference in length of hospital stay between the two groups $(p>0.05)$. Time to return to work or normal activity was significantly shorter in group II $\{5.79$ days in the harmonic scalpel groups and 9.56 days in conventional hemorrhoidectomy group). Two patients (4.76 percent) developed subsequent anal stenosis requiring anal dilation at the outpatient department in the $\mathrm{CH}$ group whereas no symptomatic anal stenosis were found in the HSH during follow-up period.

Table (2): Comparison of outcomes.

\begin{tabular}{|l|l|l|l|}
\hline Parameter & Group I & Group II & P value \\
\hline Operating time (min) & $16.9 \pm 4.4$ & $14.4 \pm 2.5$ & $\begin{array}{l}\mathrm{t}=3.2, \\
\mathrm{p}=<\mathrm{O} . \mathrm{O} \\
\mathrm{HS}\end{array}$ \\
\hline Pain score (0-10) & $4.77 \pm 0.86$ & $2.37 \pm 0.85$ & $\begin{array}{l}\mathrm{t}=12.86, \\
\mathrm{p}=<\mathrm{O} . \mathrm{OOI} \\
\mathrm{HS}\end{array}$ \\
\hline Postoperative bleeding & $3(7.1 \%)$ & $0(0 \%)$ & $\begin{array}{l}\mathrm{Z}=1.758, \\
\mathrm{p}=<0.05 \\
\mathrm{~S}\end{array}$ \\
\hline Post operative urinary retention & $4(9.5 \%)$ & $3(7.1 \%)$ & $\begin{array}{l}\mathrm{Z}=0.398, \\
\mathrm{p}=>0.05 \\
\mathrm{NS}\end{array}$ \\
\hline Surgical site infection & $1(2.5 \%)$ & $0(0 \%)$ & $\begin{array}{l}\mathrm{Z}=1.03, \\
\mathrm{p}>0.05 \\
\mathrm{NS}\end{array}$ \\
\hline Anal stenosis & $2(4.7 \%)$ & $0(0 \%)$ & $\begin{array}{l}\mathrm{t}=1.421, \\
\mathrm{p}>0.05 \\
\mathrm{NS}\end{array}$ \\
\hline Hospital stay(days) & $1.6 \pm 0.7$ & $1.4 \pm 0.6$ & $\begin{array}{l}\mathrm{t}=1.41, \\
\mathrm{p}=>0.05 \\
\mathrm{NS}\end{array}$ \\
\hline Time to return to work(days) & $9.56 \pm 0.7$ & $5.79 \pm 0.4$ & $\begin{array}{l}\mathrm{t}=30.3, \\
\mathrm{p}=<0.0 \mathrm{I} \\
\mathrm{HS}\end{array}$ \\
\hline
\end{tabular}




\section{Statistical methods:}

ffiM SPSS statistics (V. 19.0, ffiM Corp., USA, 2010) was used for data analysis. Data were expressed as Mean \pm :SD for quantitative parametric measures in addition to Median Percentiles for quantitative non-parametric measures and both number and percentage for categorized data.

The following tests were done:

1.Comparison between two independent mean groups for parametric data using Student t test.

2. Chi-square test to study the association between each 2 variables or comparison between 2 independent groups as regards the categorized data.

3. Comparison between 2 proportions as regards univariant categorized data.

The probability of error at 0.05 was considered significant; while at 0.01 and 0.001 were highly significant.

\section{Discussion:}

There are many options to treat hemorrhoidal disease described in the literature, ranging from simple clinical treatment (nutritional and hygienic informations) to more complex surgical techniques, like the use of circular staplers_1O,1l Currently, surgical treatment is considered the standard treatment for grade III and IV hemorrhoids, although it is considered a minor procedure, the postoperative course is protracted, and the postoperative complications are not negligible. The resulting pain-related complications after conventional hemorrhoidectomy are often the major factors that prolong hospital stay and delayed recovery. Recently various new treatment modalities have been developed with the aim of overcoming post-operative pain, such as stapled hemorrhoidectomy, Ligasure and harmonic scalpel, sealing devices.12 Much of the reported benefits of the harmonic scalpel in hemorrhoid surgery involve less desiccation, less eschar formation, improved wound healing, and decreased postoperative pain.B Recent studies compared Milligan- Morgan hemorrhoidectomy with harmonic scalpel method of dissection found harmonic scalpel hemorrhoidectomy prominently reduces postoperative pain and numbers of parenteral analgesic injections, which can be explained by the minimal collateral thermal spread, limited tissue charring and absence of sutures might lead to less post-operative pain.6,14-16,25

Also in this study lower pain scores were observed in patients operated on by harmonic scalpel, and less opioid analgesia were needed for patients of $\mathrm{HSH}$ group than patients operated on by $\mathrm{CH}$. In this study the operative time of HSH group was significantly shorter when compared with $\mathrm{CH}$ group. Also in other study done by Chung et.al.,14 they found that HSH was associated with shorter operative times (8.67 minutes shorter) and significantly less blood loss ( $23.08 \mathrm{~mL}$ less) compared with $\mathrm{CH}$. The reduced operative time associated with harmonic scalpel is likely related to better hemostatic control and no need to ligate the hemorrhoidal pedicles. The incidence of urinary retention in the current study was $9.5 \%$ in group I and $7.1 \%$ in group II which compares very favorably with the previously reported rates of $2 \%$ to $36 \% .2,23,24$ Spinal anesthesia, intraoperative intravenous fluid and postoperative pain are important factors contributing to increased rate of postoperative urinary retention.

The incidence of postoperative hemorrhage in the current study was $(7.1 \%)$ in $\mathrm{CH}$ group and no postoperative hemorrhage was observed in $\mathrm{HSH}$ group. The reported incidence of postoperative hemorrhage in $\mathrm{HSH}$ in a large study done by David et.al. was $0.6 \% 17$ while the recorded incidence in another study done by Nelson et al. was 2.8\%.18 No patient needs reoperation in these studies. The reported incidence of postoperative hemorrhage in $\mathrm{CH}$ varied from 5\% to $9 \%$.19-21 So from this study and other published studies we can conclude that HSH is associated with less postoperative hemorrhage than $\mathrm{CH}$. This can be explained by the high vibration frequency produced by this device which promotes hemostasis and sealing of small and medium vessels, with the advantage of producing minimal tissue injury.22,25 Infection at the surgical wound was a rare event after HSH.14,17 Also in this study no post operative infection occurred at the surgical site in HSH group, while one patient developed infection at the surgical wound in $\mathrm{CH}$ group and was treated at home with oral 
antibiotic therapy. The incidence of anorectal incontinence is rarely mentioned in most of the large hemorrhoidectomy studies, either because of its extreme rarity or because of difficulties in assessing its severity. In 1997, Lacerda-Filho and Cunha-Melo23 reported an incontinence rate of 4 percent in patients after hemorrhoidectomies.Theoretically, there is a wony that application of the harmonic scalpel clamp may risk incorporating internal anal sphincter beneath the haemorrhoidal tissues. However, the very limited data available have not shown any significant compromise of continence and no clinical sphincter injury with any flatus or stool incontinence was noted in published studies. Also, in this study no flatus or stool incontinence were recorded during the follow up period in both groups. Two patients in $\mathrm{CH}$ group in this study developed subsequent anal stenosis requiring anal dilation at the outpatient department whereas no symptomatic anal stenosis were found in the HSH group during follow-up period. However, there was no statically significant difference between the two groups as regards symptomatic anal stenosis. The same was reported in other published studies comparing $\mathrm{CH}$ and $\mathrm{HSH}$ as regards post operative symptomatic anal stenosis.17,18,26

\section{Conclusion:}

Hemorrhoidectomy with harmonic scalpel can provide a safe, fast, low-morbidity alternative to conventional hemorrhoidectomy. There are significant benefits of harmonic scalpel hemorrhoidectomy such as reduced postoperative pain, analgesic requirement, and time to return to work or normal activity. However, further prospective controlled studies are needed for more precise conclusions.

\section{References:}

1- Gupta PJ: Infrared coagulation versus rubber band ligation in early stage hemorrhoids. Braz J Med Bioi Res 2003; 36(10): 14331439.

2- MacRae HM, McLeod RS: Comparison of hemorrhoidal treatment modalities: A metaanalysis. Dis Colon Rectum 1995; 38: 687 694.

3- Ho YH, Seow-Choen F, Tan M, et al:
Randomized controlled trial of open and closed haemorrhoidectomy. BrJSurg 1997; 84: 1729-1730.

4- Au-Yong I, Rowsell M, Hemingway DM: Randomised controlled clinical trial of stapled hemorrhoidectomy versus conventional hemorrhoidectomy: A three and a half year follow-up. Colorect Dis 2004; 6: 37-38.

5- Sutherland LM, Burchard AK, Masuda K, et al: A systematic review of stapled hemorrhoidectomy. Arch Surg 2002; 137 : 1395-1406.

6- Armstrong DN, Ambroze WL, Schertzer ME, Orangio GR:Harmonic scalpel versus electrocautery hemorrhoidectomy: A prospective evaluation. Dis Colon Rectum 2001; 44: 558-564.

7- Schwanz RO: Totallaparoscopic total hysterectomy with the harmonic scalpel. $J$ Gynecol Surg 1994; 10: 33-34.

8- Khan S, Pawlak SE, Eggenberger JC, et al: Surgical treatment of hemorrhoids: Prospective, randomized trial comparing closed excisional hemorrhoidectomy and the hannonic scalpel technique of excisional hemorrhoidectomy. Dis Colon Rectum 2001; 44: 845-849.

9- Kwok SY, Chung CC, Tsui KK, Li MK,: A do uble blind randomised trial comparing Ligasure and harmonic scalpel hemorrhoidectomy. Dis Colon Rectum 2007; 48: 344-348.

10-Armstrong DN: Multiple hemorrhoidal ligation: A prospective, randomizedtrial evaluating a new technique. Dis Colon Rectum 2003; 46(2): 179-186.

11-Peng BC, Jayne DG, Ho YH: Randomized trial of rubber band ligation vs. stapled hemorrhoidectomy for prolapsed piles. Dis Colon Rectum 2003; 46(3): 291-297.

12-Kraemer M, Parulava T, Roblick M, et al: Prospective, randomized study:Proximate $\AA$ PPH stapler vs. LigasureTM for hemorrhoidal surgery. Dis Colon Rectum 2005; 48: 1517-22.

13-Tan JJ, Seow-Choen F: Prospective, randomized trial comparing diathermy and harmonic scalpel hemorrhoidectomy. Dis Colon Rectum 2001; 44(5): 677-679. 14-Chung CC, Ha JP, Tai YP, Tsang WW, Li 
MK: Double-blind, randomized trial comparing harmonic scalpel hemorrhoidectomy, bipolar scissors hemorrhoidectomy, and scissors excision:ligation technique. Dis Colon Rectum 2002; 45: 789-794.

15-Wang JY, Tsai HL, Chen FM, Chu KS, Chan HM, Huang CJ, et al: Prospective, randomized, controlled trial of Starion ${ }^{\text {TM }}$ vs LigasureTM hemorrhoidectomy for prolapsed hemorrhoids. Dis Colon Rectum 2007; 50.

16-Hardy A, Chan CL: The surgical management of hemorrhoids : A review. Dig Surg 2005; 22(1-2) 26-33.

17-David N Armstrong, Charles Frankum, Marion E, Schertzer, Wayne L, Ambroze, Guy R, Orangio: Harmonic scalpel ${ }^{\circledR}$ hemorrhoidectomy five hundred consecutive cases. Dis Colon Rectum 2002; 45: 354-359.

18-Nelson de Souza Liboni1, Jose Humberto Tavares Guerreiro Fregnani: Preliminary results of postoperative pain and complications after hemorrhoidectomy with harmonic scalpel Einstein 2006; 4(3):192195.

19-Hosch SB, Knoefel WT, Pichlmeier U, et al: Surgical treatment of piles: Prospective, randomized study of Parks vs. MilliganMorgan hemorrhoidectomy. Dis Colon Rectum 1998; 41:159-164.
20-Basso L, Pescatori M: Outcome of delayed hemorrhage following surgical hemorrhoidectomy [letter]. Dis Colon Rectum 1994; 37: 288-289.

21-Rosen L, Sipe P, Stasik JJ, Riether RD, Timpi HD: Outcome of delayed hemorrhage following surgical hemorrhoidectomy. Dis Colon Rectum 1993; 36: 743-746.

22-Fleshman J: Advanced technology in the management of hemorrhoids: Stapling, laser, harmonic scalpel, and ligature. Gastrointest Surg 2002; 6(3): 299-301.

23-Lacerda-Filho A, Cunha-Melo JR: Outpatient haemorrhoidectomy under local anaesthesia. Eur JSurg 1997; 163: 935940.

24-Bleday R, Pena JP, Rothenberger DA, Goldberg SM, Buls JG: Symptomatic hemorrhoids: Current incidence and complications of operative therapy. Dis Colon Rectum 1992; 35: 477-481.

25-Mustafa T, Taner Y, Ali I, Orner M, Selim $\mathrm{K}$ : A comparison of different hemorrhoidectomy procedures. Saudi Med J2008; 29: 1264-1269.

26-Jaw-Yuan Wang, Hsiang-Lin Tsai, FangMing Chen: Prospective, randomized controlled trial of StarionTM versus LigasureTM hemorrhoidectomy for prolapsed hemorrhoids. Dis Colon Rectum 2007; 1: 2-14. 